\title{
Real Time Current Prediction with Recurrent Neural Networks and Model Tree

\author{
S Cini ${ }^{1}$ and Makarand Chintamani Deo ${ }^{{ }^{*}}$
} \\ ${ }^{1}$ Department of Civil Engineering, Indian Institute of Technology Bombay, Powai400-076, India
}

(Manuscript Received June 20 2013; Revised July 14, 2013; Accepted August 21, 2013)

\begin{abstract}
The prediction of ocean currents in real time over the warning times of a few hours or days is required in planning many operation-related activities in the ocean. Traditionally this is done through numerical models which are targeted toward producing spatially distributed information. This paper discusses a complementary method to do so when site-specific predictions are desired. It is based on the use of a recurrent type of neural network as well as the statistical tool of model tree. The measurements made at a site in Indian Ocean over a period of 4 years were used. The predictions were made over 72 time steps in advance. The models developed were found to be fairly accurate in terms of the selected error statistics. Among the two modeling techniques the model tree performed better showing the necessity of using distributed models for different sub-domains of data rather than a unique one over the entire input domain. Typically such predictions were associated with average errors of less than $2.0 \mathrm{~cm} / \mathrm{s}$. Although the prediction accuracy declined over longer intervals, it was still very satisfactory in terms of theselected error criteria. Similarly prediction of extreme values matched with that of the rest of predictions. Unlike past studies both east-west and north-south current components were predicted fairly well.
\end{abstract}

Keywords: Ocean current prediction, Ocean currents, Artificial neural networks; Real time forecasting; Model tree

\section{Introduction}

Real time information of ocean currents is necessary for a variety of purposes such as deciding navigation paths, identifying safe swimming locations, predicting pollution trajectories, estimating sediment movements and forecasting electrical output of current driven power generators. It is however a complex task owing to a large number of causal parameters of atmospheric and oceanic origin. The magnitude and direction of currents in the real time mode can be derived using numerical models that solve the governing differential equations of hydrodynamics using finite difference or finite element methods. These techniques require a large amount of modeling effort as well as data of various kinds like bathymetry, wind, tide, initial and boundary conditions, apart from large computational resources and they are suitable when

\footnotetext{
*Corresponding author. Tel.: +91 222576 7330, Fax: +91 22 25767302,

E-mail address: mcdeo@civil.iitb.ac.in

Copyright C KSOE 2013.
}

spatially distributed information is aimed at.In some applications like predicting output of the currentdriven power farms, launching of offshore structures, planning of recreational activities the locationspecific forecasts would be sufficient. In such situations, various statistical, stochastic and soft computing tools such as artificial neural network (ANN) and model tree (MT) can be used.

The ANN is classified as a soft computing tool capable of modeling any random input with corresponding random output without assuming any fixed relationship between them beforehand.It is an interconnection of computational elements called neurons, each of which essentially combines the input received and transfers it using a nonlinear function for further communication.Before application the network is trained by feeding examples of input-output as per a learning algorithm resulting in assigning values to the connection weights. The training is commonly imparted through the error back-propagation in which the 
connection weights are changed iteratively according to their previous values and a correction term. The iterations can be stopped by using certain stop criterion like the fixed number of epochs or reaching an error goal over the cross validation data set.The network is tested after such training and validation exercise. Text books like Wassermann [1] and $\mathrm{Wu}$ [2] may be referred to know more details of the functioning of ANN.

The MT is a piecewise linear statistical method that consists of dividing the input domain into different sub-domains and fitting a linear regression in each.Witten and Frank [3] provide details of this method.

Efforts to use the above methods however need continuous improvements owing to the site-specific nature of applications and since prediction of higher magnitudes and at long prediction intervals is fraught with uncertainty and inaccuracy, especially under complex locations. Effort should therefore be made to do more experimentation in this regard at different world locations. While ANN is a popular nonlinear soft computing tool that may provide good fit to data over the entire domain MT is a piecewise linear statistical method that can work well at specific subdomains of input such as extreme values. It was thus decided to explore these two techniques for the problem of real time current prediction under consideration. The overall aim of this work was thus to develop models to carry out real time prediction of ocean currents for the time intervals in the range of a few hours and days and using selected ANN architectures and MT, watching the performance at higher values and over longer prediction horizons.Some details of the selected network architecture and MT are given below.

\section{The network and model tree}

\subsection{The Jordan Elman Network}

The present prediction task is handled as a time series forecasting problem in which a selected sequence of past values is used to identify a hidden pattern in it and thereby provide forecast of the subsequent value.It essentially calls for accounting of the memory or immediate past condition in the system and hence a recurrent type of network, Jordan Elman, was selected. The Jordan Elman neural network (Fig. 1) is in the form of a multilayer perceptron consisting of an input layer, hidden layer and an output layer of neurons, and a set of context neurons that remember the past activity and thereby extract temporal information from the data. While the Elman part feeds back the activity of the hidden neurons through context units, the Jordan part copies the same of the output neurons. Such extraction uses a 'recency gradient' in which the recent values are given high importance and such influence exponentially decays as we move backward over the time sequence. The transfer function of the context units can be of linear or nonlinear type.As mentioned earlier the network is required to be calibrated by feeding known examples or input-output pairs and such feeding continues till the network learns.

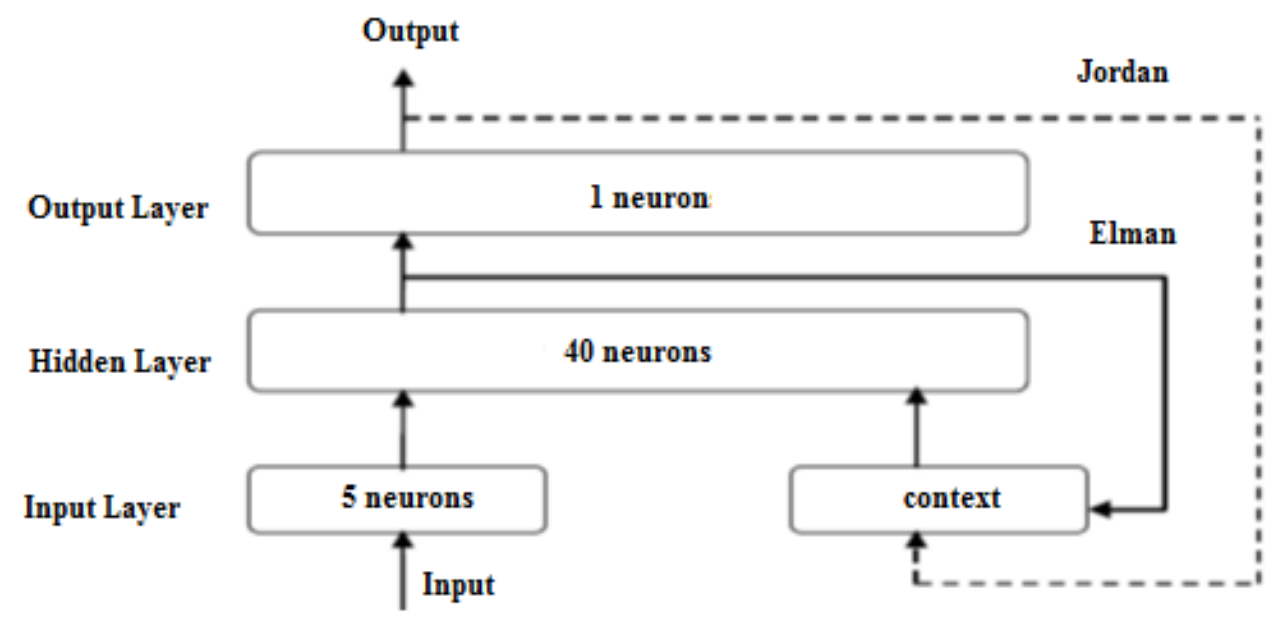

Fig. 1. The Jordan Elman architecture 

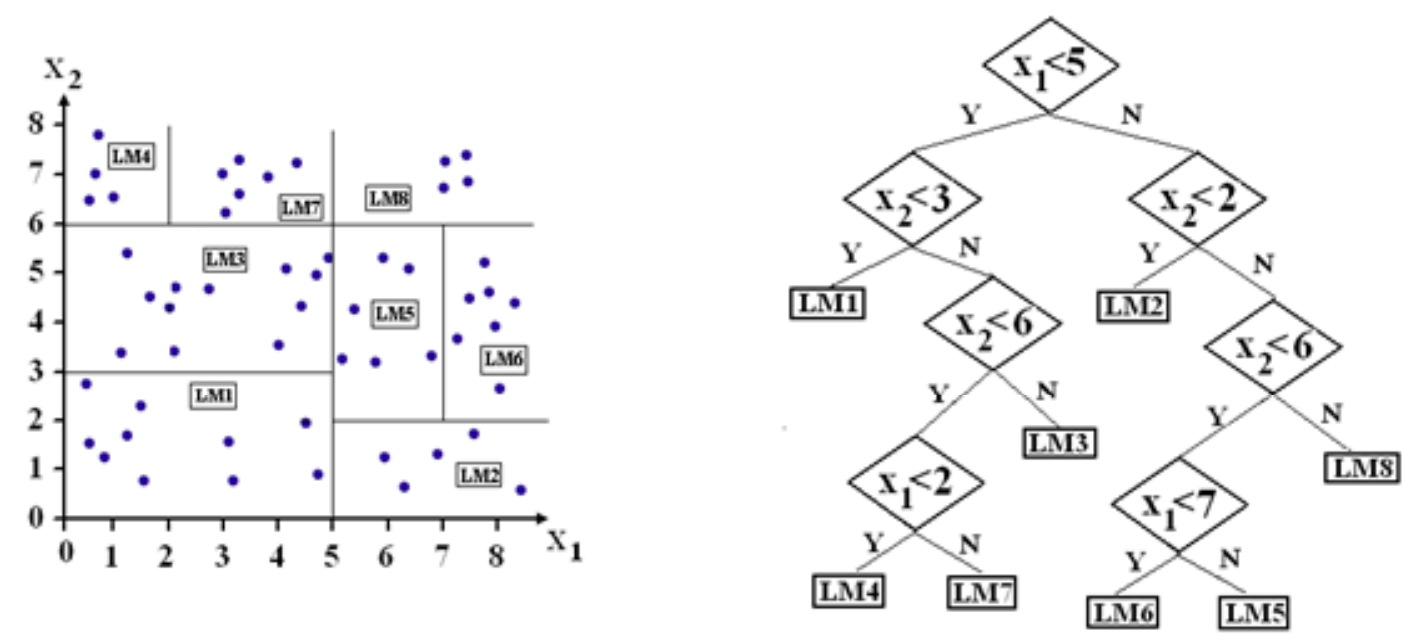

Fig. 2.The illustration of model tree. (a) Input classification, (b) Tree structure

$\left(\mathrm{x}_{1}, \mathrm{x}_{2}\right.$ are inputs; $\mathrm{LM}$ denotes linear model)

\subsection{The Model Tree}

The MT extends the concept of classification tree and regression tree that consists of representing the computational process by a classification and tree structure (Fig. 2a) consisting of a root node (decision box) branching out to numerous other nodes and leaves.The entire input or parameter domain is divided into sub-domains and a multivariate linear regression model is developed for each subdomain. The MT therefore builds a piecewise linear model to approximate a given nonlinear relationship between a dependent variable and corresponding independent variables.In case of MT the output as a whole does not depend on input but it involves a set of functional relationships within the input domain. Depending on considerations like a domain splitting criterion there are alternative algorithms to build a MT.The M5 algorithm of Quilan [4] is convenient to use and it is as follows:If, $\mathrm{N}=$ total number of training examples (collection of all independent variable values together with the corresponding dependent variable values) then using some dividing or splitting criterion $\mathrm{N}$ is divided into many sub-domains.For every sub-domain an error measure is selected to decide if further division is necessary.In the M5 algorithm the error criterion is the standard deviation $(\sigma)$ of the class value reaching a node (decision box).Fig. $2 b$ shows a tree structure representation of this process and corresponding to the given parameter domain for a 2-D input.In particular the difference between the standard deviation of the total training set and the (weighted) standard deviation of any i-th subdomain is taken as the splitting criterion, i. e.,

$\sigma_{r}=\sigma(N)-\sum_{i}\left(N_{i} / N\right) \sigma\left(N_{i}\right)$

where $\sigma_{\mathrm{r}}=$ reduction in standard deviation $\sigma, \sigma(\mathrm{N})$ $=\sigma$ of all training examples, $N_{i}=$ no. of examples in the i-th sub-domain, $\sigma\left(\mathrm{N}_{\mathrm{i}}\right)=\sigma$ of i-th subdomain.During training many possible ways of input divisions are examined and the one that yields a maximum. $\sigma_{\mathrm{r}}$ is finally selected to build linear model at each sub region.Every such model could be typically:

$$
o=a_{0}+a_{1} i_{1}+a_{2} i_{2}+\ldots
$$

where $\mathrm{o}=$ dependent variable; $\mathrm{a}_{0}, \mathrm{a}_{1}, \mathrm{a}_{2}, \ldots . .=$ coefficients that could be derived using least square fit; $i_{1}, i_{2}, \ldots=$ independent variables. The splitting stops when the class values of all collections in a subdomain do not vary much (typically by $5 \%$ ), i.e., all samples have the same classification or when very few collections result.To begin with an attribute (say $\mathrm{x}_{1}<5$ in Fig. 2) is selected as the root node and two branches are drawn (as per 'Yes' or 'No') and thereafter such a process of splitting continues. The selection of the attribute as the root node is done as per its ability to maximize $\sigma_{\mathrm{r}}$.If the splits are large, overfitting might happen in which generalization does not take place and instead individual training patterns only are learnt.In that case the structure is pruned by say merging together a few 
lower sub-regions producing similar models. If the above pruned structure has large discontinuities between neighboring models (especially when the training examples are less) then smoothing is done by revising nearby equations such that their output comes more close to each other [3].

\section{The Past Works}

The techniques of ANN and MT have been applied by many investigators in the past to predict ocean parameters including currents, tides, waves, wind and sediment transport.Jain and Deo [5] and Deo [6] provide details of such works on ANN while Sakhare and Deo [7] and Jain et al. [8] indicate applications of MT in oceanic and land water.As regards applications of these tools to study currents the same are sparse and these are due to Charhate et al. [9] Huang and Murray [10] and Aydogan et al. [11].Charhate et al. [9] predicted currents at a tide dominated location in Gulf of Khambhat along the west coast of India.The current predictions were made over a time step of $20 \mathrm{~min}$, a few hours, and a day. Authors found the cross-shore current predictions less satisfactory than the longshore component due to complex flow conditions.Huang and Murray [10] predicted currents at an inlet located within a larger regional system based on water level measurements at a different and distant location.Aydogan et al.[11] predicted current velocities, one to twelve hours in advance, at Strait of Istanbul based on concurrent measurements of current profiles, meteorological conditions, and surface elevations.

It was noticed from the past works mentioned above is that methods such as ANN and MT hold promise for universal acceptance in the application domain but they need continuous improvement since prediction of higher magnitudes and that over higher prediction intervals is fraught with considerable uncertainty and inaccuracy, especially under complex locations. Effort should therefore be made to carry out more experimentation in this regard at different world locations.

\section{Database}

The current measurements available on the web site: www.nio.org of the National Institute of Oceanography at Goa, India was used in the present study. The recorder was of Aanderaa DCM12 type. The location was in Indian Ocean and code named: EQCM1 at Lat. $0^{\circ}$ and Long. $93^{\circ} \mathrm{E}$ (Fig. $3)$.It is a deep water equatorial site. The recording period considered was 13 Feb 2000 to 23 Sept. 2003. The measurements belonged to two current components: meridional (toward north) and zonal (toward east) recorded at the $100 \mathrm{~m}$ depth.The recording interval was $2 \mathrm{hr}$ for the southwest (SW) monsoon and $1 \mathrm{hr}$ for the northeast (NE) monsoon.

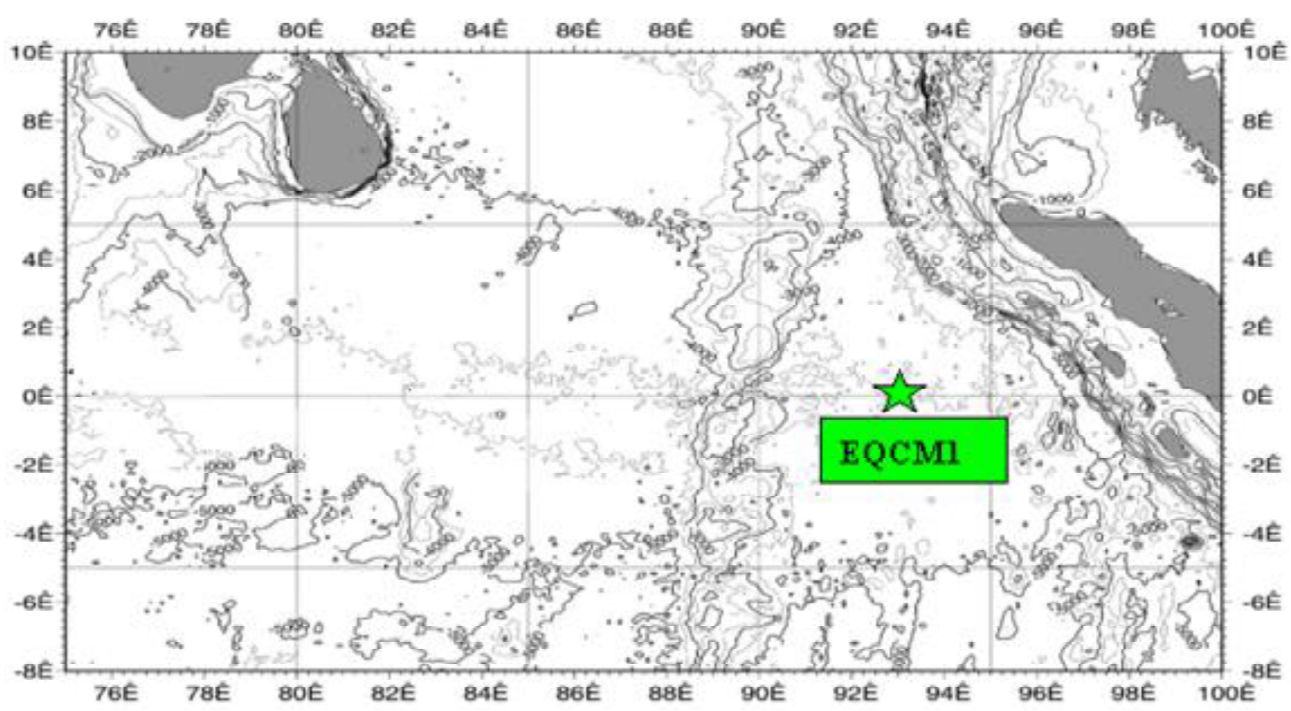

Fig. 3 The location of study in Indian Ocean: EQCM1 (source: www.nio.org) 
Table 1. Basic statistics of data

\begin{tabular}{|l|c|c|c|c|}
\hline \multirow{2}{*}{} & \multicolumn{2}{|c|}{ S-W Monsoon } & \multicolumn{2}{c|}{ N- E Monsoon } \\
\cline { 2 - 5 } & $\begin{array}{c}\text { MerVel } \\
(\mathrm{cm} / \mathrm{s})\end{array}$ & $\begin{array}{c}\text { ZonVel } \\
(\mathrm{cm} / \mathrm{s})\end{array}$ & $\begin{array}{c}\text { MerVel } \\
(\mathrm{cm} / \mathrm{s})\end{array}$ & $\begin{array}{c}\text { ZonVel } \\
(\mathrm{cm} / \mathrm{s})\end{array}$ \\
\hline StdDev & 13.75 & 15.84 & 14.05 & 13.73 \\
\hline Kurtosis & 0.45 & 0.07 & 0.98 & 1.22 \\
\hline Skewness & 0.02 & -0.15 & 0.03 & 0.64 \\
\hline
\end{tabular}

The measurements showed two distinct characteristics during SW and northeast NE monsoons.It was found that during the SW monsoon (MayOctober) $75 \%$ of zonal values and $60 \%$ of meridional values were positive (east flowing and north flowing, respectively). In case of the NE monsoon (November-April) this distribution was roughly equal.Table 1 shows the basic statistics of mean, standard deviation, kurtosis and skewness for the current components during both the monsoon seasons.As can be seen from the Table 1 the zonal velocities had higher means (due to westerly equatorial jet flows) than the meridional speeds but comparable standard deviation. The zonal component of SW monsoon had kurtosis almost equal to zero which indicates a normal distribution while the rest of all data have positive kurtosis indicating taller distribution or very few data in the tails. The skewness of all the components is in between $-1 / 2$ and $+1 / 2$, which implies that the distribution was approximately symmetric.At the basic statistical level the data did not seem to involve a very high amount of complexities.

\section{The Training of the Models}

The present prediction exercise involved time series forecasting in which a selected sequence of preceding observations was recursively used as input to obtain the future value of the current speeds.In such methods it is assumed that the very occurrence of the measured values reflected all the causative factors and hence modeling of the sequence of occurrence is same as that of the underlying physical process.

Considering that the SW and NE monsoon data could belong to two different populations separate neural networks were developed for SW and NE monsoon conditions. The measurements of the first
3 years were used for network training (and this includes the use of $5 \%$ observations for cross validation) while those of the last one year were employed for network testing.

The prediction intervals pertained to $1,3,6,12$, 24 and 72 times steps. Thus it was $2 \mathrm{hr}$ to 6 days for the SW monsoon and $1 \mathrm{hr}$ to 3 days for the NE monsoon.

To begin with the most common feed forward back-propagation type of network was considered for training.However its performance was not very satisfactory and could not be further improved by varying the network control parameters and learning methods.Hence the Jordan Elman type of network that provides explicit treatment to the past memory as descried earlier was adopted. It had three layers of neurons, namely, input layer, hidden layer, and output layer. By trials aimed at getting the highest correlation coefficient between the observed and predicted current values the number of input nodes was selected as 5 (and they belonged to the five preceding observations) while the number of neurons in the hidden layer was set to 40 . The output neuron was 1 in number and this corresponded to the predicted current value.The number of maximum training epochs was set as 1000.The training process involved the context unit that controls a forgetting factor of 0.8 (usually between 0 and 1). The activation function of the context unit employed a context axon that is used in JordanElman networks to process previous information. The bais axon type transfer function which shifts the results of the processing to have the same mean as the desired outputs was used. A non-linear learning rule, Levenberg-Marquardt, was employed for both hidden layer and output layer. The termination criterion was the mean squared error (MSE) set to 0.0001 . The networks were trained two to three times and the best networks were selected based on the minimum MSE and maximum correlation between observed and predicted values. The weights saved at the end of the successful training were used for network testing.

In case of MT, the input-output scheme was kept similar to that of ANN so that the performance could be compared.This also included similarity of the training and testing sets.In MT the input domain gets divided into sub-domains and within each subdomain linear regression is carried out.If it results in improving the performance, the linear models 
can either be pruned or smoothened.In the present case this was not found to be helpful in gaining accuracy and hence was not adopted.Typically the number of rules (individual regressions) required to carry out a given prediction was a few hundred in number.

\section{Results}

The quantitative performance of the developed networks and MT was judged through three different types of error statistics: correlation coefficient (R), mean squared error (MSE) and mean absolute error (MAE). The expressions of these measures and their relative advantages are given in Appendix I. Table 2 and 3 show how both ANN and MT models performed for different prediction intervals in case of zonal as well as meridional currents in terms of R, RMSE and MAE during SW (Table 2a and $2 \mathrm{~b}$ and NE (Table $3 \mathrm{~b}$ and $3 \mathrm{~b}$ monsoon cases.These tables are populatedwith the testing data base.Further, the qualitative assessment of closeness between the target and model predicted values of meridional and zonal velocities during the testing exercise can be seen in the time history plots and scatter diagrams of Fig. 4 (for the SW monsoon) and Fig. 5 (for the NE monsoon).

A general look into the results indicates that both ANN as well as MT models performed well and were associated with high values of $\mathrm{R}$ and low values of RMSE and MAE (Tables: 2-3) and that the rising and falling trends in the observations were fairly picked up by the models (Fig. 4-5). Among

Table 2a Variation of Correlation Coefficient, RMSE \& MAE of Meridional Velocity - SW monsoon

\begin{tabular}{|c|c|c|c|c|c|c|}
\hline \multicolumn{6}{|c|}{ Meridional Velocity - SW Monsoon } \\
\hline \multirow{2}{*}{$\mathrm{t}=2 \mathrm{hr}$} & \multicolumn{2}{|c|}{$\mathrm{R}$} & \multicolumn{2}{c|}{ RMSE } & \multicolumn{2}{c|}{ MAE } \\
\cline { 2 - 7 } & ANN & MT & ANN & MT & ANN & MT \\
\hline $1 \mathrm{t}$ & 0.94 & 0.99 & 2.9 & 1.2 & 2.2 & 0.7 \\
\hline $3 \mathrm{t}$ & 0.89 & 0.98 & 4.1 & 1.7 & 3.2 & 1.1 \\
\hline $6 \mathrm{t}$ & 0.86 & 0.98 & 4.4 & 1.7 & 3.4 & 1.1 \\
\hline $12 \mathrm{t}$ & 0.79 & 0.97 & 5.5 & 2.2 & 4.4 & 1.4 \\
\hline $24 \mathrm{t}$ & 0.60 & 0.96 & 7.1 & 2.4 & 5.7 & 1.5 \\
\hline $72 \mathrm{t}$ & 0.38 & 0.91 & 8.3 & 3.6 & 6.6 & 2.1 \\
\hline
\end{tabular}

the two models MT showed better performance than ANN over all cases of advance prediction intervals and monsoon conditions. Typically MT predictions were associated with $\mathrm{R}$ values above 0.9 and RMSE and MAE values below $3.5 \mathrm{~cm} / \mathrm{s}$ and $2.0 \mathrm{~cm} / \mathrm{s}$, respectively. These Figures also show that small interval predictions had better fidelity with the target values compared with the long interval ones as can be expected due to the reduced dependency in case of the latter occurrences, although generally the match was fairly good for both the cases. The reason behind the better performance of MT seems to its ability to break up the complex input domain into many small classes where the same linear models do an efficient regression as against the ANN in which essentially there is only one trained relationship to carry out the same task. This study points to carry out good experimentation before using a particular soft or hard computing tool for such prediction exercises.

It may be noted that in this work a careful training has resulted in predicting both meridional and zonal components with good accuracy unlike the earlier work of Charhate et al. [9] based on the use of ANN and genetic programming in which the authors had unsatisfactory prediction of the zonal currents. The reasons for this is the adequate training imparted herein and at the same time around $74 \%$ of the zonal current was east-flowing unlike that of Charhate et al. [9] and this consistency could have contributed to better accuracy.

Table 2b Variation of Correlation Coefficient, RMSE \& MAE of Zonal Velocity - SW monsoon

\begin{tabular}{|c|c|c|c|c|c|c|}
\hline \multicolumn{7}{|c|}{ Zonal Velocity - SW Monsoon } \\
\hline \multirow{2}{*}{$\mathrm{t}=2 \mathrm{hr}$} & \multicolumn{2}{|c|}{$\mathrm{R}$} & \multicolumn{2}{c|}{ RMSE } & \multicolumn{2}{c|}{ MAE } \\
\cline { 2 - 7 } & ANN & MT & ANN & MT & ANN & MT \\
\hline $1 \mathrm{t}$ & 0.98 & 0.99 & 2.2 & 1.0 & 1.7 & 0.6 \\
\hline $3 \mathrm{t}$ & 0.97 & 0.99 & 3.2 & 1.3 & 2.5 & 0.8 \\
\hline $6 \mathrm{t}$ & 0.96 & 0.99 & 3.4 & 1.4 & 2.7 & 0.9 \\
\hline $12 \mathrm{t}$ & 0.95 & 0.99 & 3.8 & 1.5 & 3.1 & 1.0 \\
\hline $24 \mathrm{t}$ & 0.93 & 0.99 & 4.6 & 1.8 & 3.7 & 1.2 \\
\hline $72 \mathrm{t}$ & 0.82 & 0.97 & 7.4 & 3.0 & 5.7 & 1.8 \\
\hline
\end{tabular}


Table 3a Variation of Correlation Coefficient, RMSE \& MAE of Meridional Velocity - NE monsoon

\begin{tabular}{|c|c|c|c|c|c|c|}
\hline \multicolumn{6}{|c|}{ Meridional Velocity - NE Monsoon } \\
\hline \multirow{2}{*}{$\mathrm{t}=1 \mathrm{hr}$} & \multicolumn{2}{|c|}{$\mathrm{R}$} & \multicolumn{2}{c|}{ RMSE } & \multicolumn{2}{c|}{ MAE } \\
\cline { 2 - 7 } & ANN & MT & ANN & MT & ANN & MT \\
\hline $1 \mathrm{t}$ & 0.99 & 0.99 & 1.9 & 0.7 & 1.4 & 0.5 \\
\hline $3 \mathrm{t}$ & 0.92 & 0.99 & 3.5 & 1.4 & 2.8 & 0.9 \\
\hline $6 \mathrm{t}$ & 0.89 & 0.98 & 4.1 & 1.7 & 3.2 & 1.1 \\
\hline $12 \mathrm{t}$ & 0.88 & 0.98 & 4.3 & 1.7 & 3.4 & 1.1 \\
\hline $24 \mathrm{t}$ & 0.81 & 0.97 & 5.2 & 2.1 & 4.1 & 1.3 \\
\hline $72 \mathrm{t}$ & 0.4 & 0.94 & 7.8 & 3.1 & 6.2 & 1.9 \\
\hline
\end{tabular}

The prediction of extreme values and also the same over longer time horizons becomes most of the times difficult in prediction exercises.It was therefore decided to examine how this was done in the present work.For this purpose the trained MT model was tested only for the extreme data below the 10-th percentile and above the 90 -th percentile considered together. Table 4 shows the model performance for such data over longer prediction intervals of $12 \mathrm{t}, 14 \mathrm{t}$ and $72 \mathrm{t}$, where $\mathrm{t}$ is the time step ( $2 \mathrm{hr}$ and $1 \mathrm{hr}$ for SW and NE monsoon respectively).It may be seen that the correlation coefficients are still very high showing a satisfactory performance of the MT model under these conditions.

Many times field users demand the predicted values of the current speed and direction rather than the meridional and zonal components.For this purpose the outcome of the above modeling can be easily converted into the desired quantities by simple trigonometric formulae.An example of such exercise is given in Fig. 6 that shows the predicted time history plots of the current speeds as well as directions for $\mathrm{SW}$ and $\mathrm{NE}$ monsoon conditions as an example.

\section{Conclusions}

The real time prediction of ocean currents up to 72 time steps in future carried out in this work with the help of ANN and MT models was found to be fairly accurate as shown by the selected error statistics.

Among the two modeling techniques the MT performed consistently well showing the necessity
Table 3b Variation of Correlation Coefficient, RMSE \& MAE of Zonal Velocity - NE monsoon

\begin{tabular}{|c|c|c|c|c|c|c|}
\hline \multirow{6}{*}{$\mathrm{t}=1 \mathrm{hr}$} & \multicolumn{2}{|c|}{$\mathrm{R}$} & \multicolumn{2}{c|}{ RMSE } & \multicolumn{2}{c|}{ MAE } \\
\cline { 2 - 7 } & ANN & MT & ANN & MT & ANN & MT \\
\hline $1 \mathrm{t}$ & 0.97 & 0.99 & 1.4 & 0.6 & 1.1 & 0.4 \\
\hline $3 \mathrm{t}$ & 0.88 & 0.98 & 2.6 & 1.1 & 2.0 & 0.7 \\
\hline $6 \mathrm{t}$ & 0.83 & 0.97 & 3.1 & 1.3 & 2.4 & 0.8 \\
\hline $12 \mathrm{t}$ & 0.81 & 0.97 & 3.2 & 1.3 & 2.5 & 0.8 \\
\hline $24 \mathrm{t}$ & 0.77 & 0.97 & 3.5 & 1.4 & 2.7 & 0.8 \\
\hline $72 \mathrm{t}$ & 0.61 & 0.95 & 4.4 & 1.8 & 3.5 & 1.1 \\
\hline
\end{tabular}

of using distributed models for different subdomains of data rather than a unique one over the entire input domain for this type of data analysis.

Typically the MT predictions were associated with $R$ values above 0.9 and RMSE and MAE values below $3.5 \mathrm{~cm} / \mathrm{s}$ and $2.0 \mathrm{~cm} / \mathrm{s}$, respectively.

Although the prediction accuracy declined over longer intervals, it was still satisfactory in terms of the selected error criteria.Similarly prediction of extreme values did not significantly deteriorate. Unlike past studies both east-west and north-south current components were predicted fairly well.

Table 4. Prediction of Extreme Values over Longer Intervals

\begin{tabular}{|c|c|c|c|c|}
\hline \multirow{3}{*}{$\begin{array}{l}\text { Prediction } \\
\text { Interval }\end{array}$} & \multirow{3}{*}{ Method } & \multirow{3}{*}{$\begin{array}{l}\text { Velocity } \\
\text { Compo- } \\
\text { nent }\end{array}$} & \multicolumn{2}{|c|}{$\begin{array}{c}\text { Extreme Value } \\
\text { Correlation } \\
\text { Coefficient }\end{array}$} \\
\hline & & & $\begin{array}{c}\text { S-W } \\
\text { Monsoon }\end{array}$ & $\begin{array}{c}\text { N-E } \\
\text { Monsoon }\end{array}$ \\
\hline & & & $\mathrm{t}=2 \mathrm{hr}$ & $\mathrm{t}=1 \mathrm{hr}$ \\
\hline \multirow{2}{*}{$12 \mathrm{t}$} & \multirow{2}{*}{ MT } & MerVel & 0.998 & 0.994 \\
\hline & & ZonVel & 0.988 & 0.987 \\
\hline \multirow{2}{*}{$24 \mathrm{t}$} & \multirow{2}{*}{ MT } & MerVel & 0.997 & 0.989 \\
\hline & & ZonVel & 0.980 & 0.987 \\
\hline \multirow{2}{*}{$72 t$} & \multirow{2}{*}{ MT } & MerVel & 0.989 & 0.965 \\
\hline & & ZonVel & 0.950 & 0.971 \\
\hline
\end{tabular}


SW-Monsoon: Current Prediction

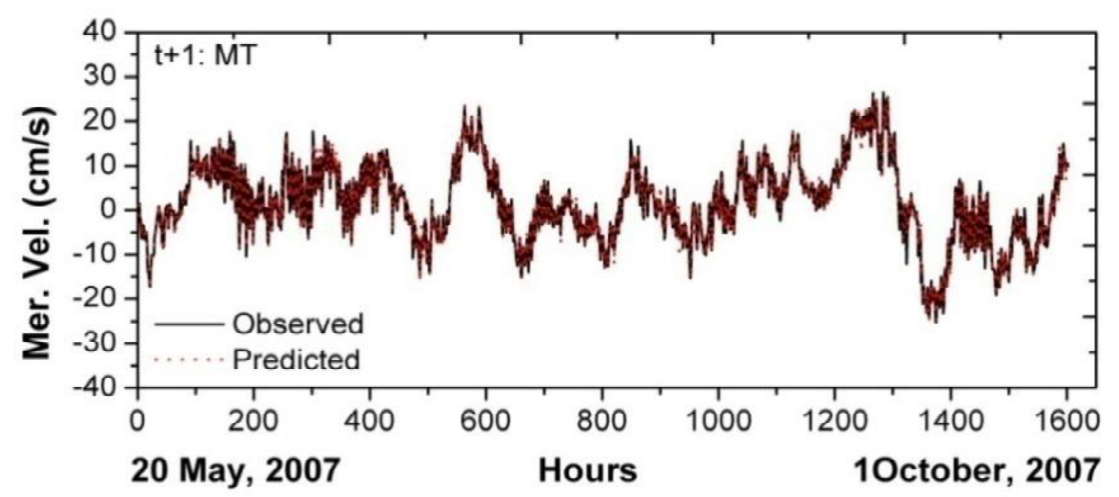

(a)

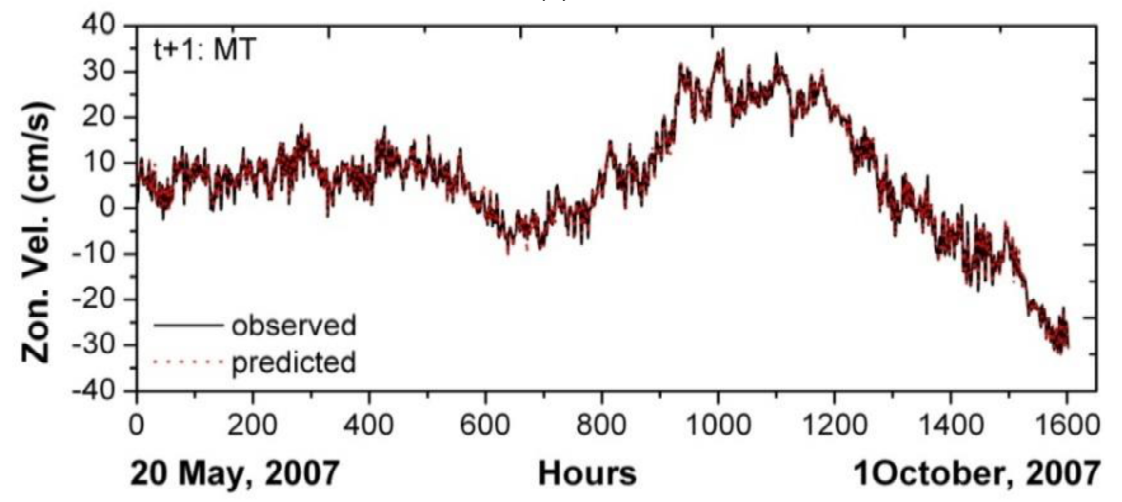

(c)

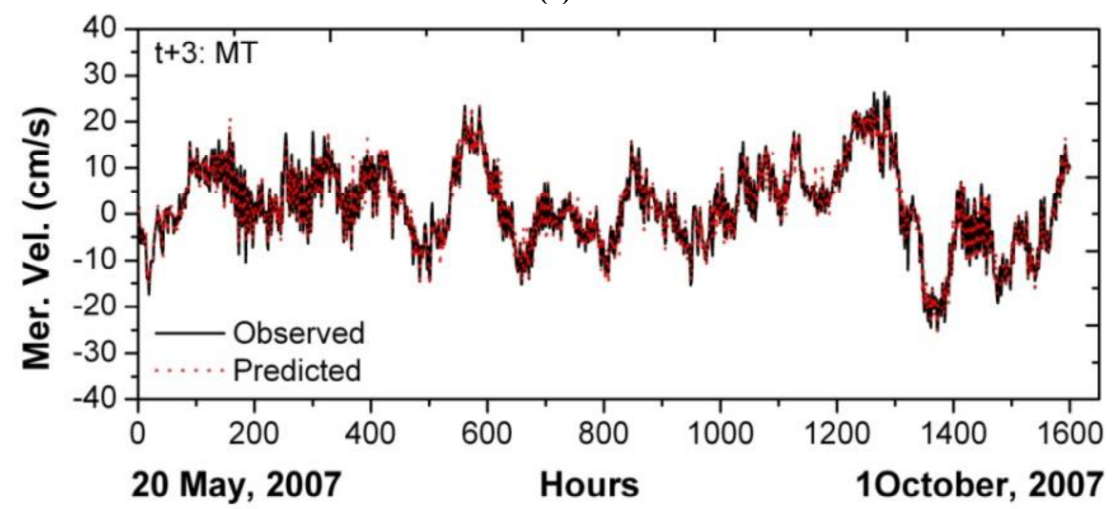

(e)

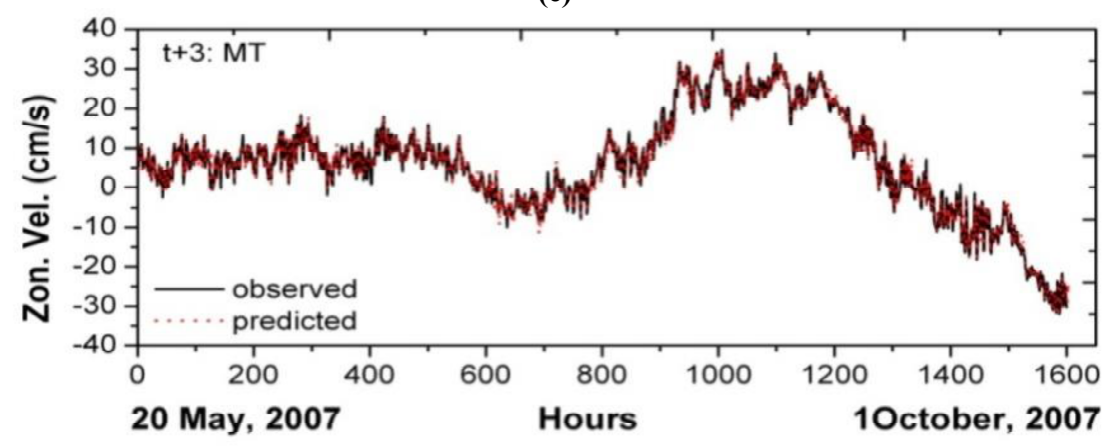

(g)

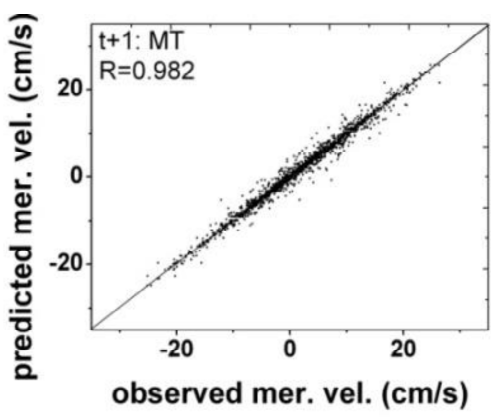

(b)

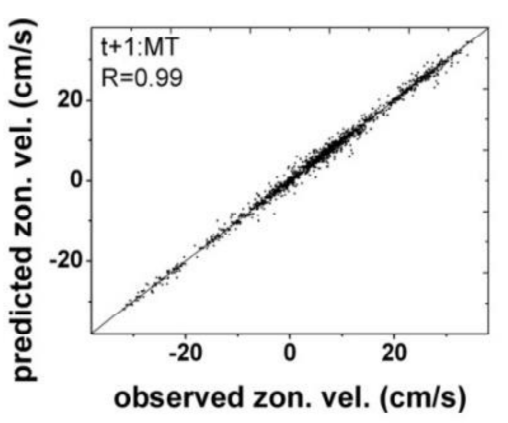

(d)

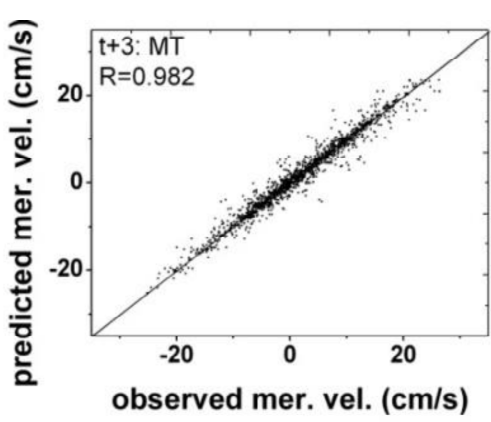

(f)

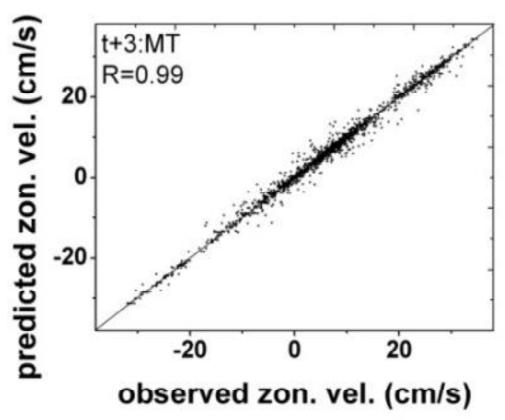

(h)

(a) Time series and (b) scattered plot for $1 \mathrm{hr}$ ahead Meridional Velocity: SW Monsoon

(c) Time series and (d) scattered plot for $1 \mathrm{hr}$ ahead Zonal Velocity: SW Monsoon

(e) Time series and (f) scattered plot for $3 \mathrm{hr}$ ahead Meridional Velocity: SW Monsoon

(g) Time series and (h) scattered plot for $3 \mathrm{hr}$ ahead Zonal Velocity: SW Monsoon

Fig.4 


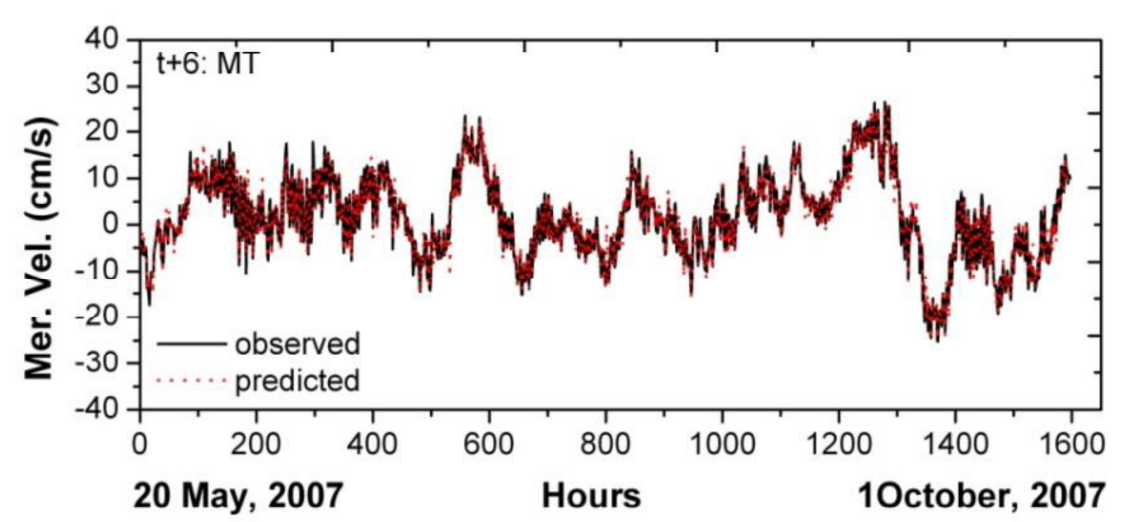

(i)

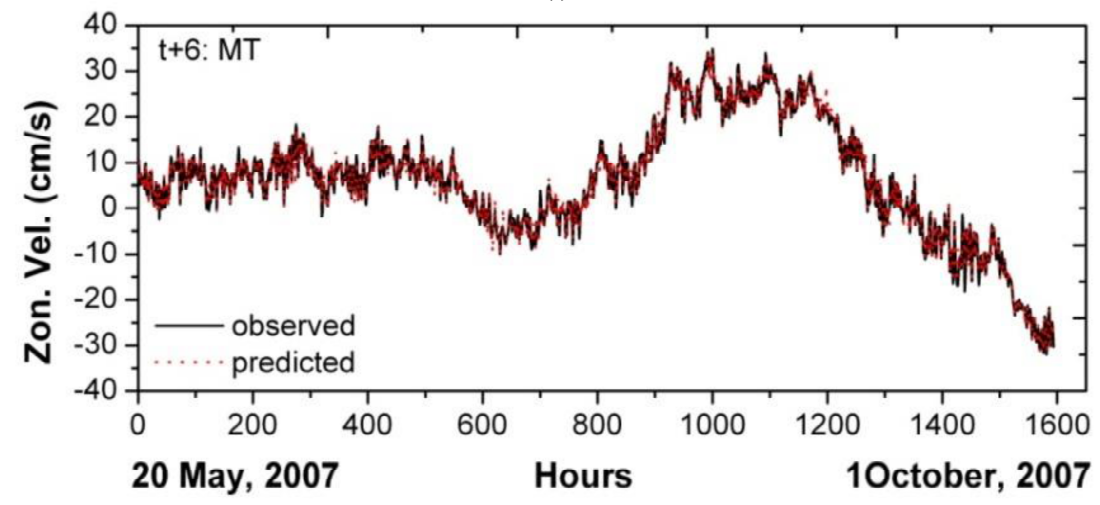

(k)

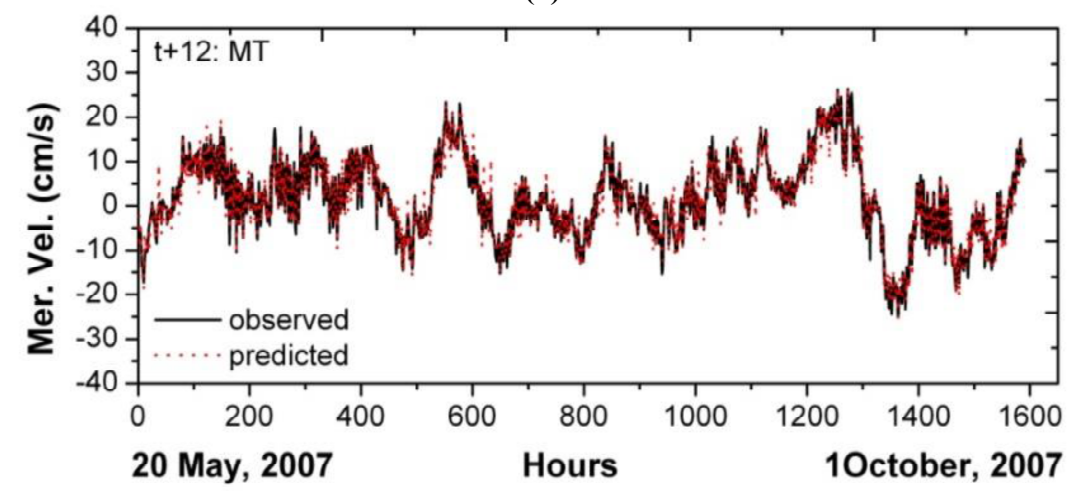

(m)

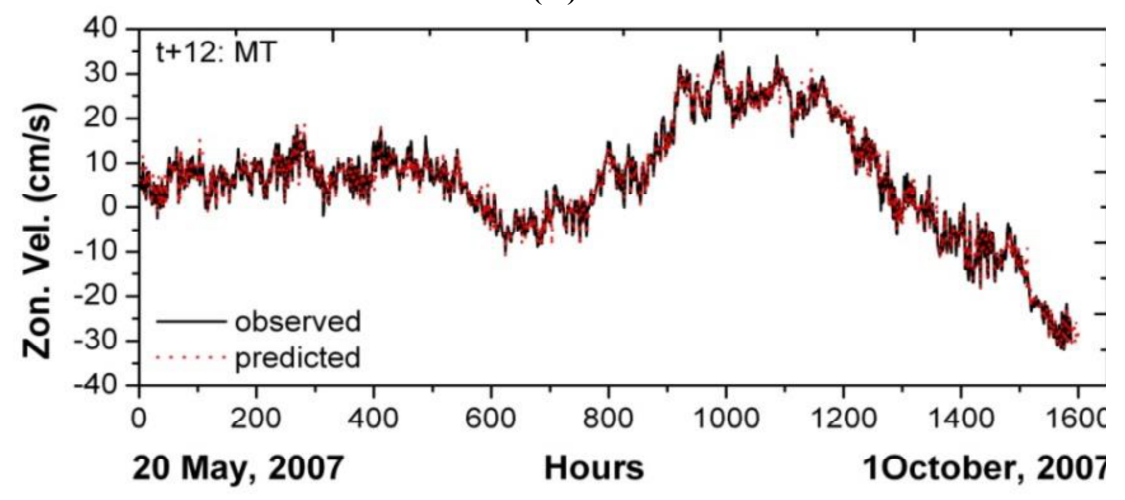

(o)

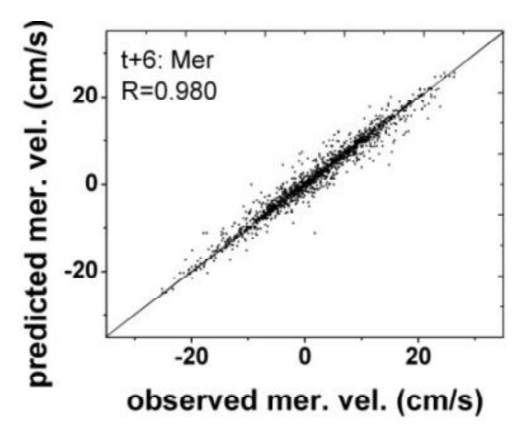

(j)

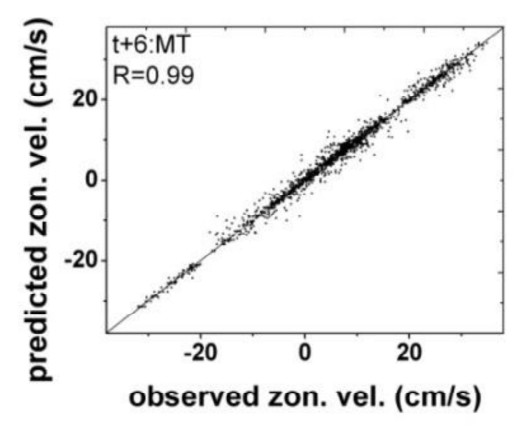

(I)

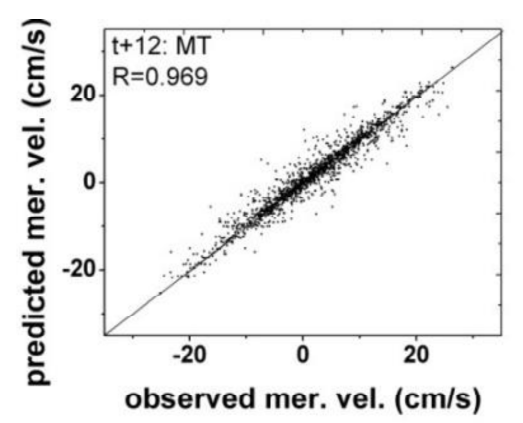

(n)

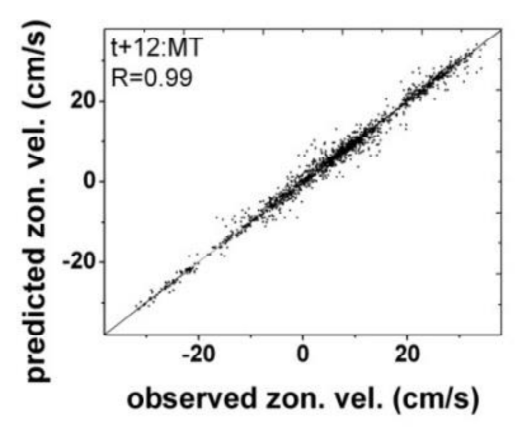

(p)

(i) Time series and (j) scattered plot for $6 \mathrm{hr}$ ahead Meridional Velocity: SW Monsoon

Fig.4 (k) Time series and (l) scattered plot for $6 \mathrm{hr}$ ahead Zonal Velocity: SW Monsoon

(m) Time series and (n) scattered plot for $12 \mathrm{hr}$ ahead Meridional Velocity: SW Monsoon

(o) Time series and (p) scattered plot for $12 \mathrm{hr}$ ahead Zonal Velocity: SW Monsoon 


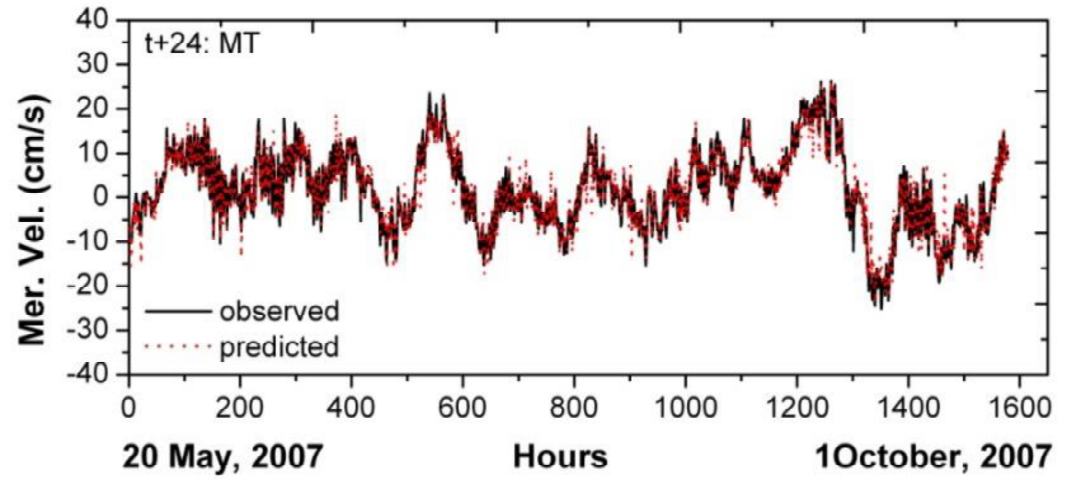

(q)

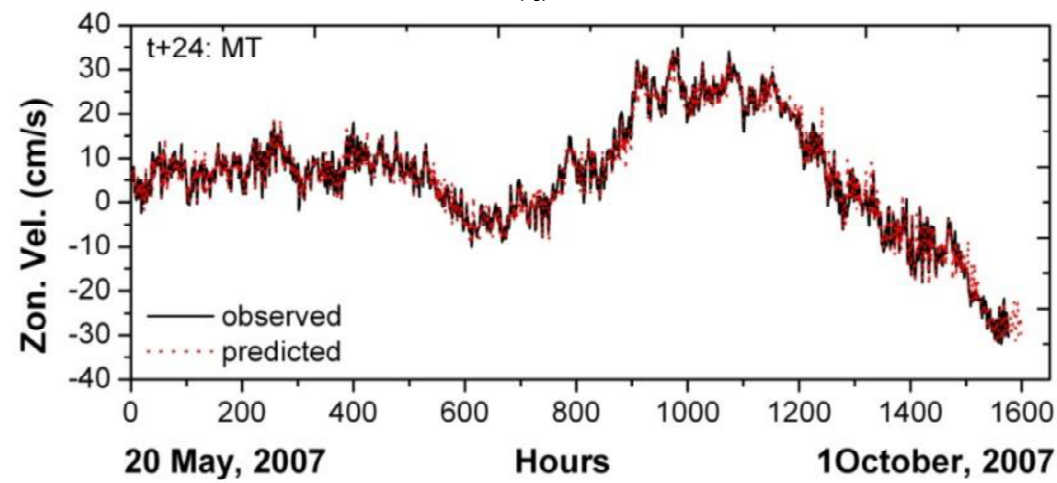

(s)

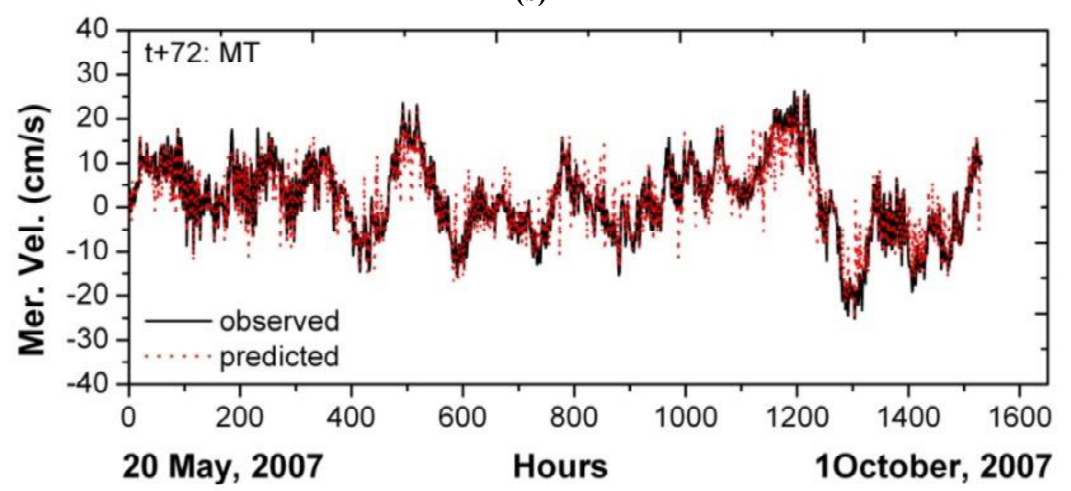

(u)

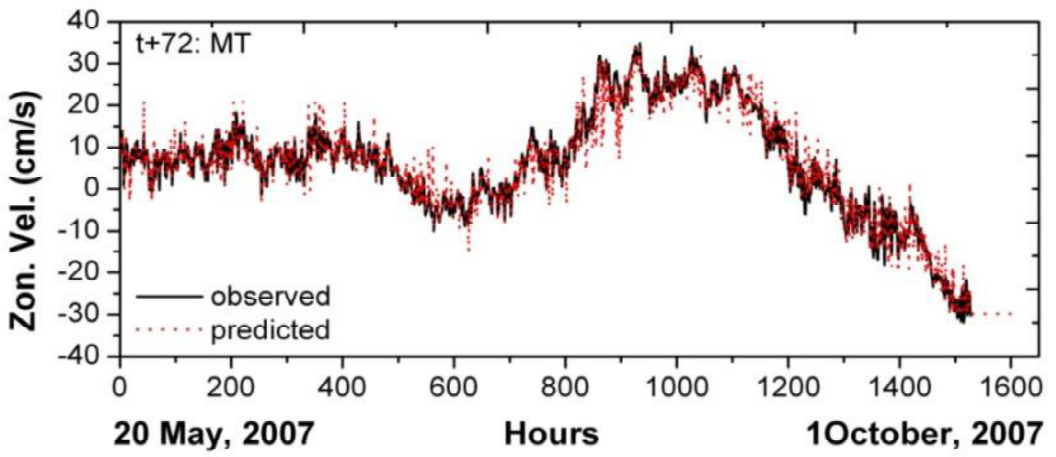

(w)

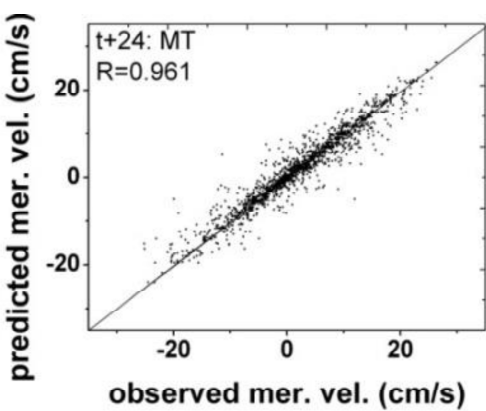

(r)

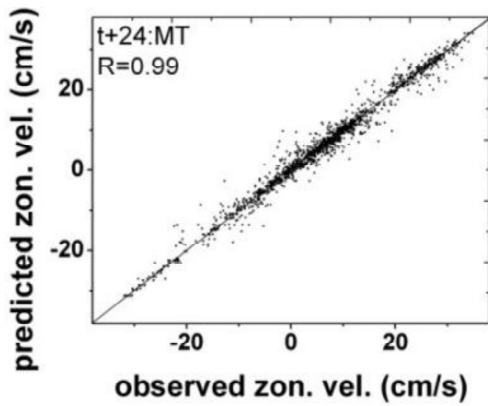

(t)

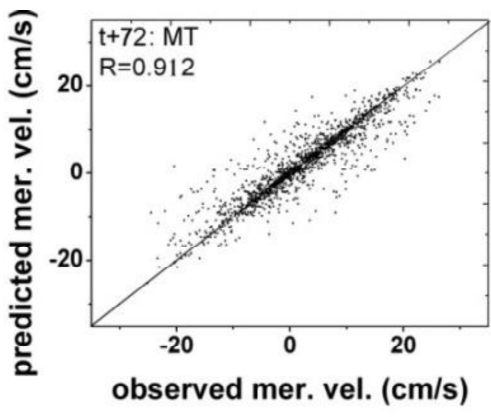

(v)

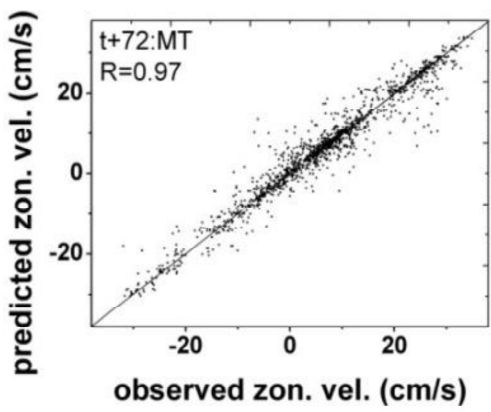

(x)

(q) Time series and (r) scattered plot for $12 \mathrm{hr}$ ahead Meridional Velocity: SW Monsoon

Fig.4

(s) Time series and (t) scattered plot for $12 \mathrm{hr}$ ahead Zonal Velocity: SW Monsoon

(u) Time series and (v) scattered plot for $72 \mathrm{hr}$ ahead Meridional Velocity: SW Monsoon

(w) Time series and (x) scattered plot for $72 \mathrm{hr}$ ahead Zonal Velocity: SW Monsoon 


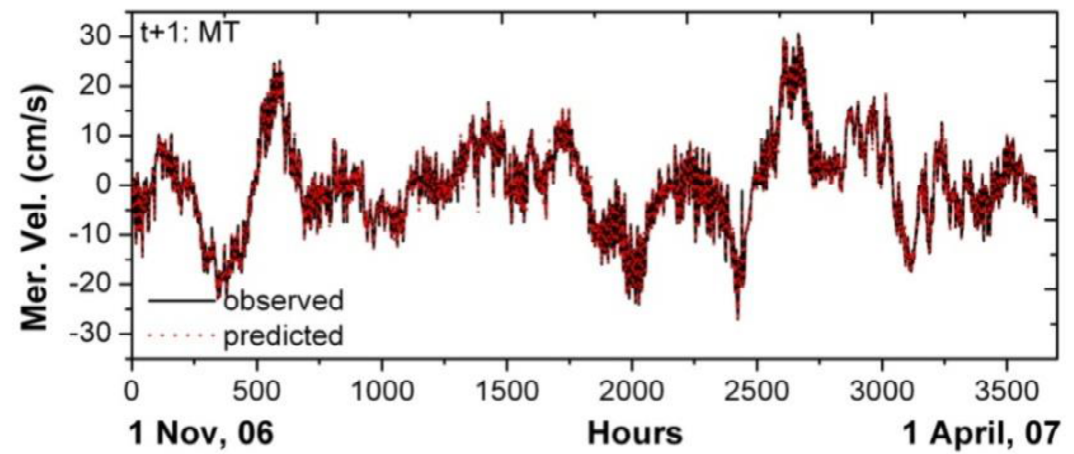

(a)

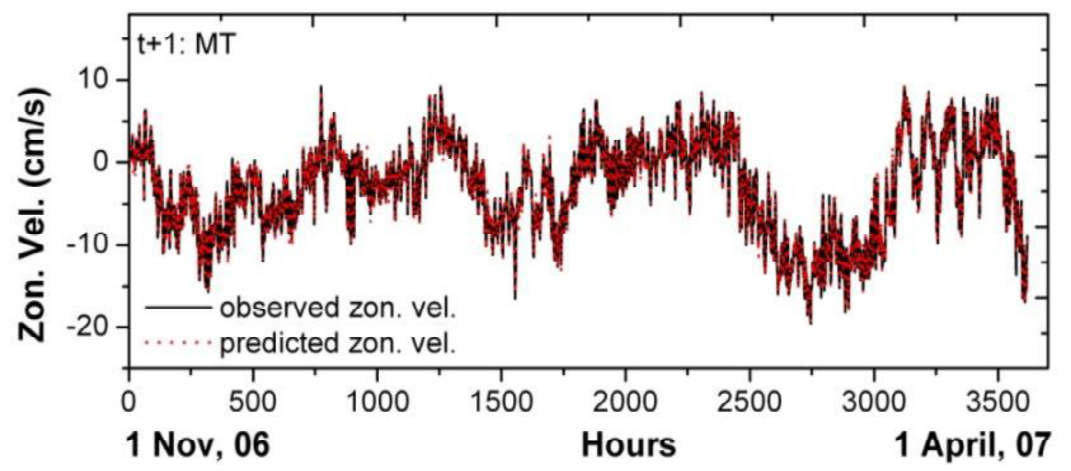

(c)

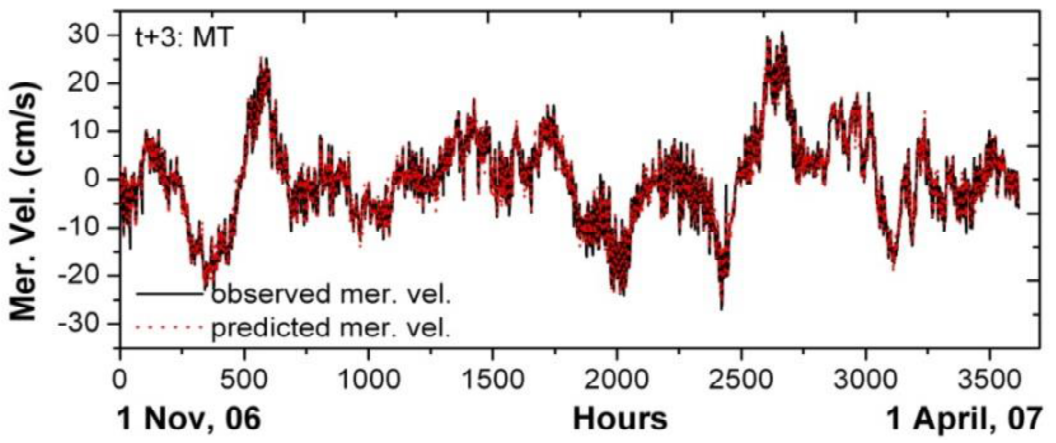

(e)

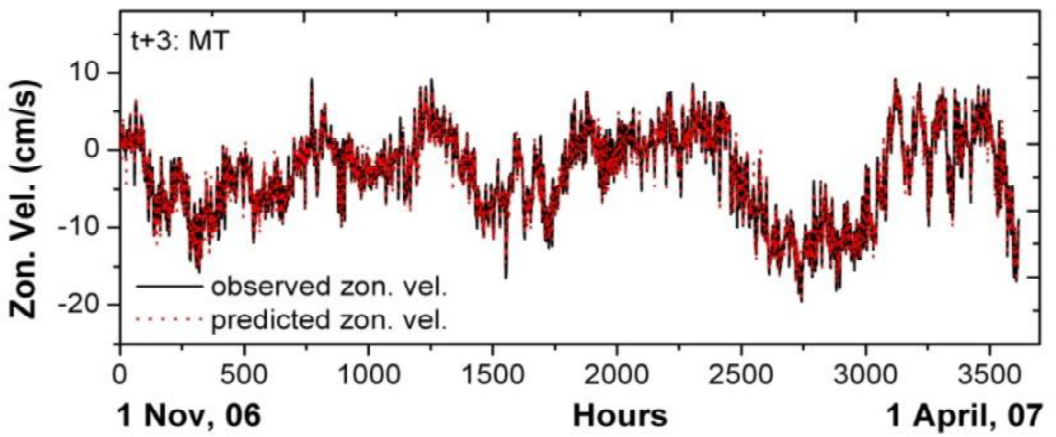

(g)

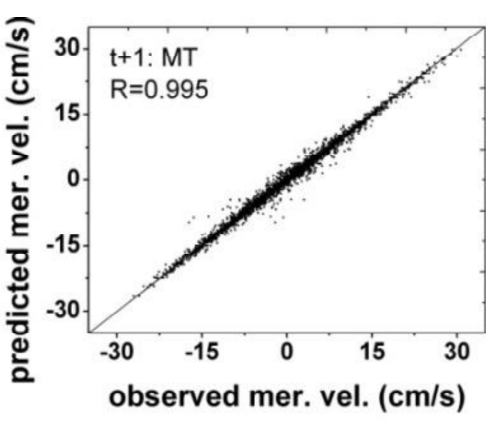

(b)

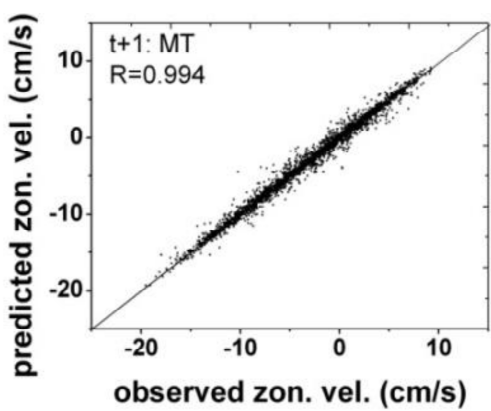

(d)

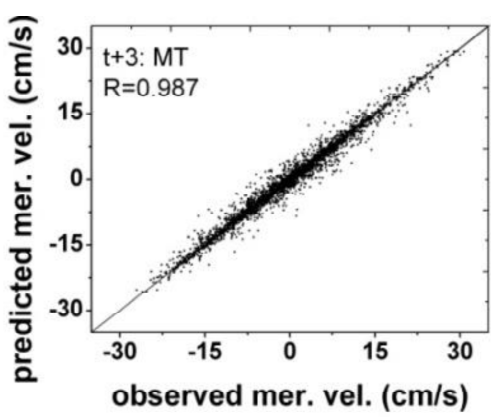

(f)

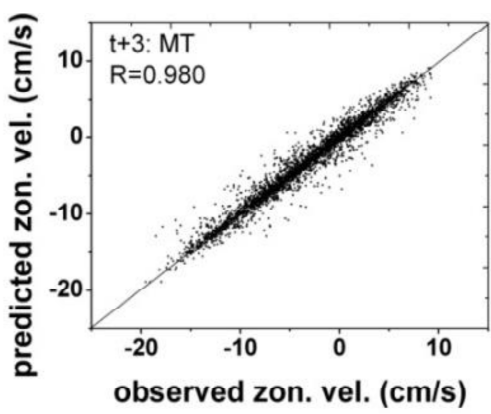

(h)

(a) Time series and (b) scattered plot for $1 \mathrm{hr}$ ahead Meridional Velocity: NE Monsoon

(c) Time series and (d) scattered plot for $1 \mathrm{hr}$ ahead Zonal Velocity: NE Monsoon

Fig.5

(e) Time series and (f) scattered plot for $3 \mathrm{hr}$ ahead Meridional Velocity: NE Monsoon

(g) Time series and (h) scattered plot for $3 \mathrm{hr}$ ahead Zonal Velocity: NE Monsoon 

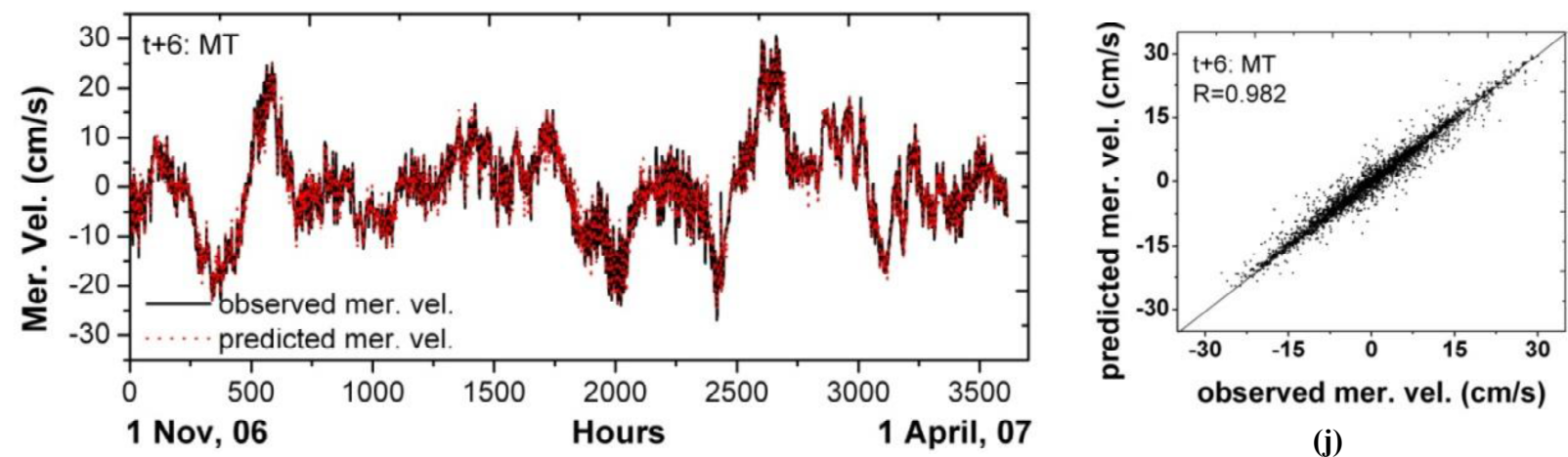

(i)

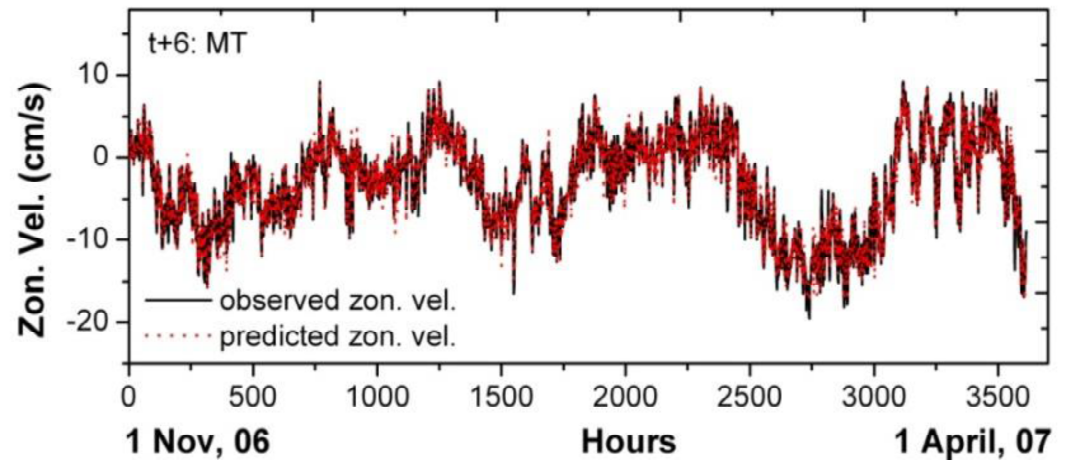

(j)

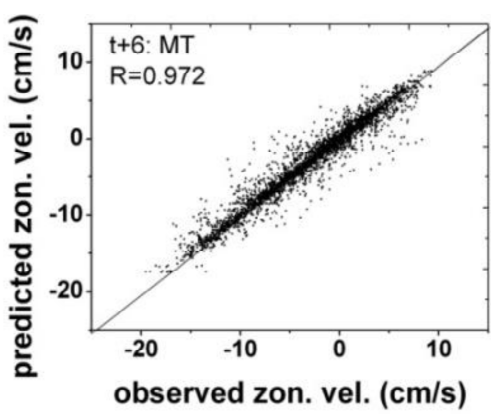

(k)
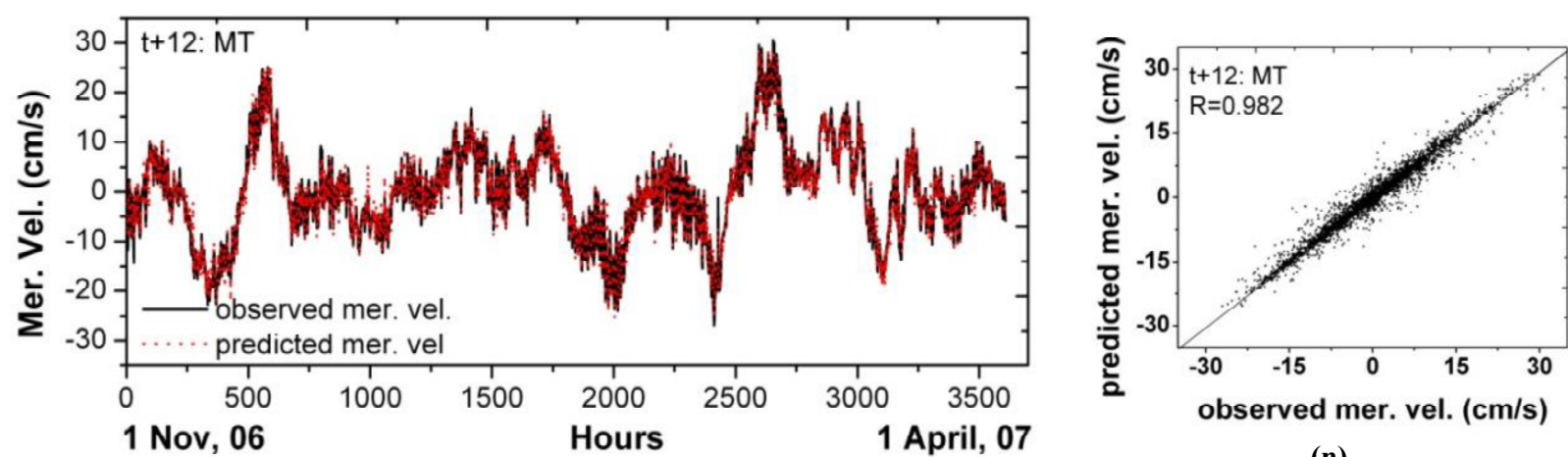

(n)

(m)
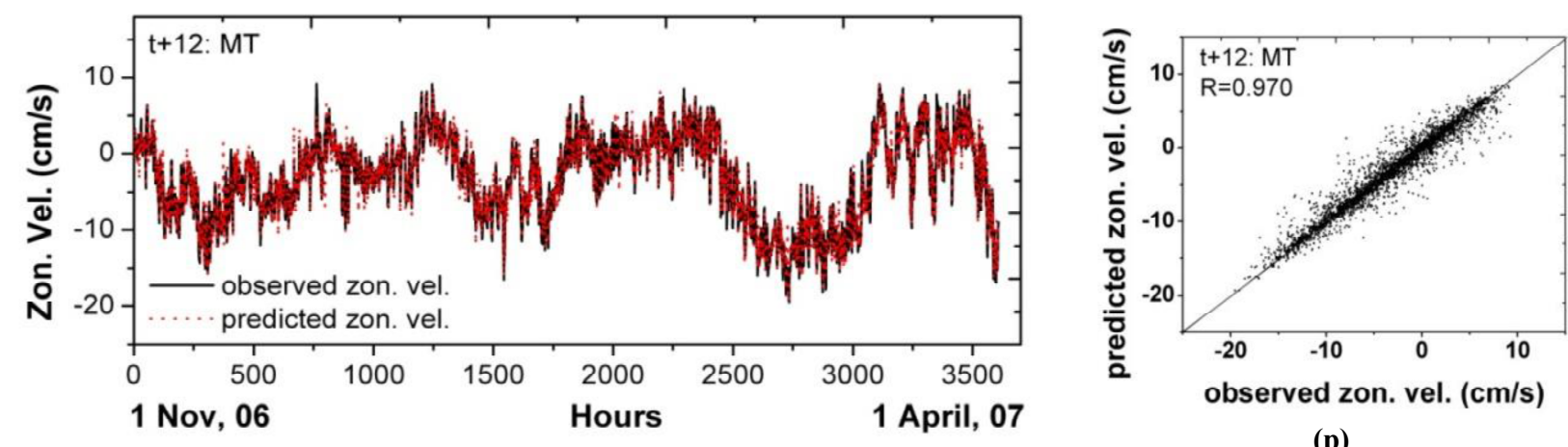

(p)

(o)

(i) Time series and (j) scattered plot for $6 \mathrm{hr}$ ahead Meridional Velocity: NE Monsoon

Fig.5

(k) Time series and (1) scattered plot for $6 \mathrm{hr}$ ahead Zonal Velocity: NE Monsoon

(m) Time series and (n) scattered plot for $12 \mathrm{hr}$ ahead Meridional Velocity: NE Monsoon

(o) Time series and (p) scattered plot for $12 \mathrm{hr}$ ahead Zonal Velocity: NE Monsoon 


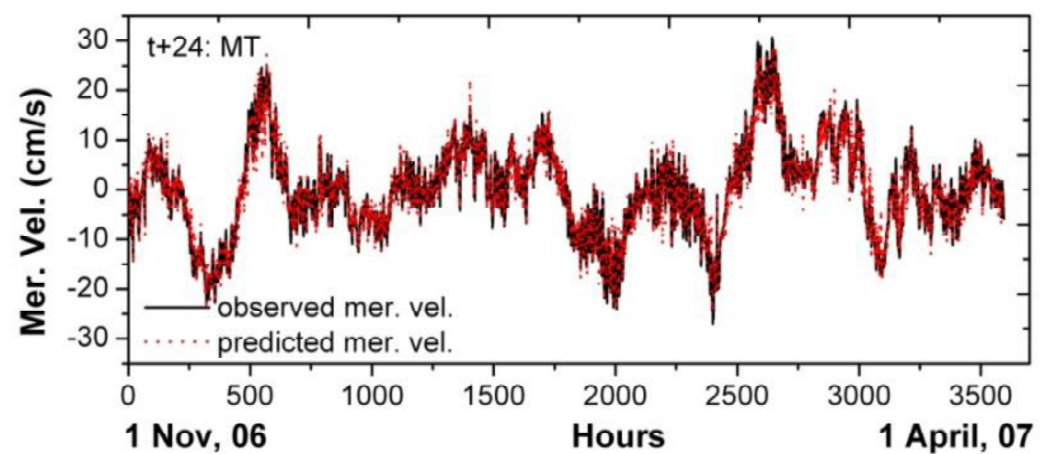

(q)

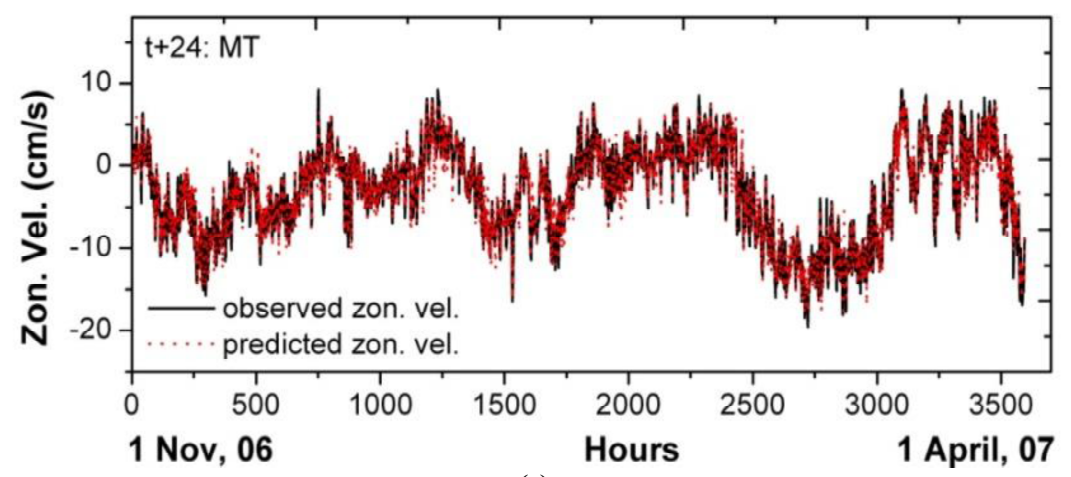

(s)

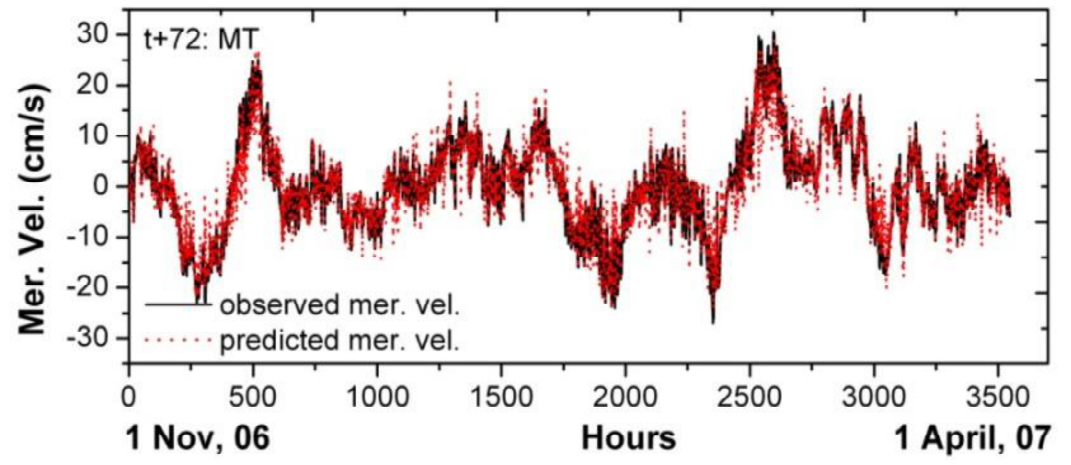

(u)

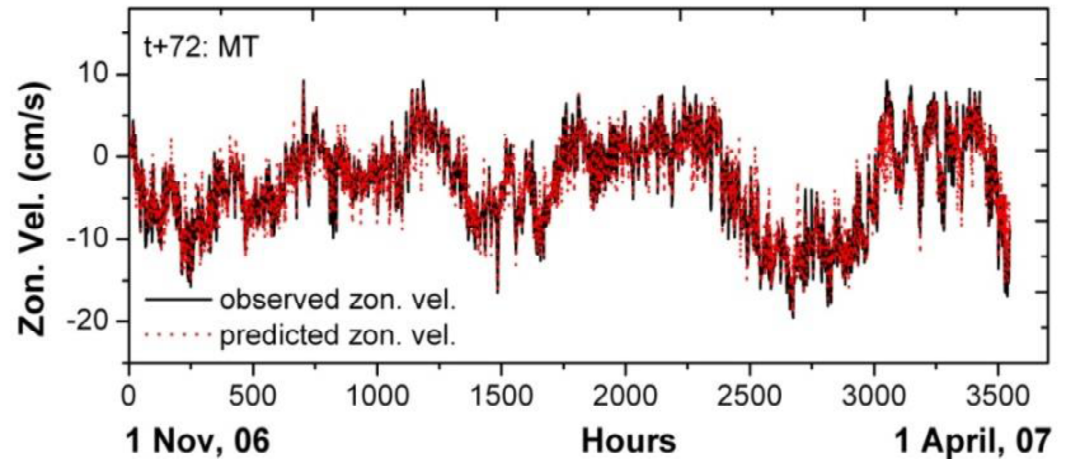

(w)

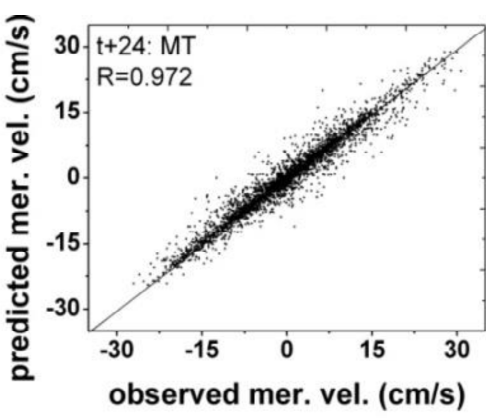

(r)

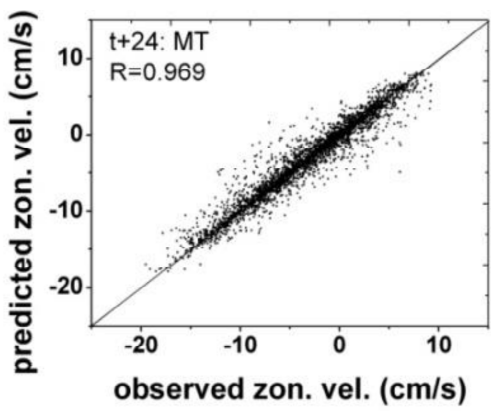

(t)

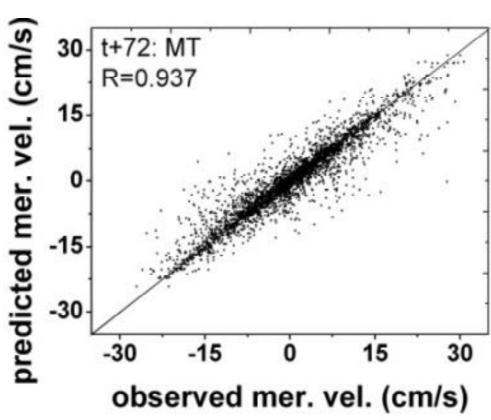

(v)

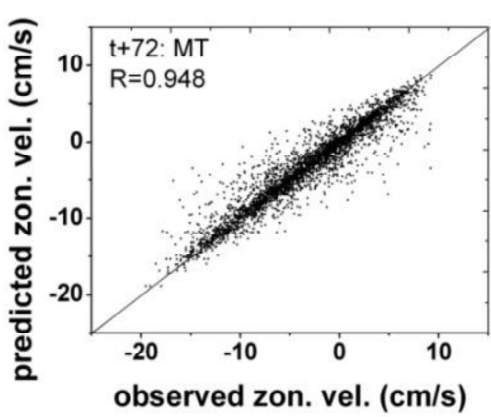

(x)

(q) Time series and (r) scattered plot for $12 \mathrm{hr}$ ahead Meridional Velocity: NE Monsoon

Fig.5

(s) Time series and ( $\mathrm{t}$ ) scattered plot for $12 \mathrm{hr}$ ahead Zonal Velocity: NE Monsoon

(u) Time series and (v) scattered plot for $72 \mathrm{hr}$ ahead Meridional Velocity: NE Monsoon

(w) Time series and (x) scattered plot for $72 \mathrm{hr}$ ahead Zonal Velocity: NE Monsoon 

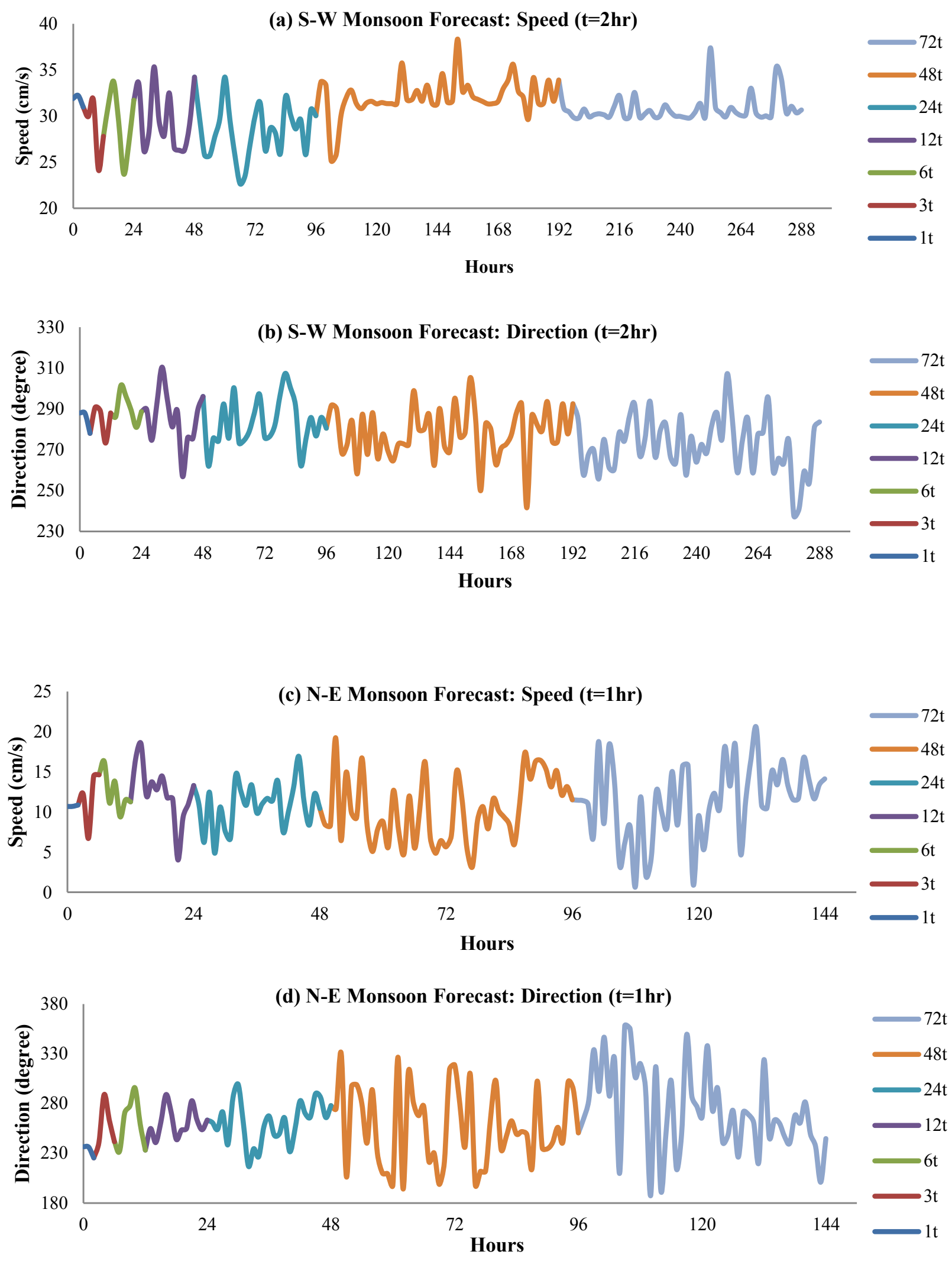

(b) Direction of S-W Monsoon
(c) Speed of N-E monsoon current
(d) Direction of N-E Monsoon 


\section{References}

[1] Wasserman, P.D., 1993, Advanced Methods in Neural Computing, Van Nostrand Reinhold. New York

[2] Wu, K.K., 1994, Neural Networks and Simulation Methods, Marcel Decker. New York

[3] Witten, I.H. and Frank, E., 2000, Data Mining: Practical Machine Learning Tools and Techniques with Java Implementations, Morgan Kaufmann, Burlington, MA, USA.

[4] Quinlan J.R. 1992, Learning with continuous classes, Proceedings of Australian Joint Conference on AI, 343-348, World Scientific, Singapore.

[5] Jain P. and Deo M. C. 2006, Neural networks in ocean engineering Ships and Offshore Structures 1:1, 25-35.

[6] Deo M C. 2010.Artificial neural networks in coastal and ocean engineering. Indian Journal of Geo-Marine Sciences,39(4), Dec., 2010, 589-596.

[7] Sakhare S and M C Deo. 2009. Derivation of wave spectrum using data driven methods. Marine Structures,Elsevier, doi: 10.1016/j.marstruc.2008.12.994

[8] Jain, P, M C Deo, G Latha, V Rajendran, V Sanil Kumar.2011. Determination of Wave Spectrum with Intelligent Computing. International Journal of Ocean and Climate Systems, Multi-Science, UK, 2(2), 137-152.

[9] Charhate S. B., Deo M. C. and Kumar V. S. 2007. Soft and hard computing approaches for real-time prediction of currents in a tidedominated coastal area. Proceedings of the Institution of Mechanical Engineers, Part M: Journal of Engineering for the Maritime Environment 221:4, 147-163.

[10]Huang, W. and Murray,C. 2008. Multiplestation neural network for modeling tidal currents across a coastal inlet. Hydrological Processes, 22 (8), 1136-1149

[11]Aydogan B., Ayat B., Ozturk M. N., Cevik E. O. and Yuksel Y. 2010. Current velocity forecasting in straits with artificial neural networks, a case study: Strait of Istanbul. Ocean Engineering 37, 443-453.

\section{Appendix I}

\section{Expressions of the errormeasures}

\section{Coefficient of Correlation (R)}

It describes the degree of co-linearity between simulated and measured data, which ranges from -1 to 1 , is an index of the degree of linear relationship between observed and simulated data Eq. (3). If $R=$ 0 , no linear relationship exists. If $\mathrm{R}=1$ or -1 , a perfect positive or negative linear relationship exists.

$$
\mathrm{R}=\frac{\mathrm{n} \sum \mathrm{xy}-\left(\sum \mathrm{x}\right)\left(\sum \mathrm{y}\right)}{\sqrt{\mathrm{n}\left(\sum \mathrm{x}^{2}\right)-\left(\sum \mathrm{x}\right)^{2}} \sqrt{\mathrm{n}\left(\sum \mathrm{y}^{2}\right)-\left(\sum \mathrm{y}\right)^{2}}}
$$

where, $\mathrm{R}$ is the linear correlation between 2 variables $\mathrm{x}$ and $\mathrm{y}, \mathrm{n}$ is the number of pairs of data.

The correlation coefficient however gets heavily affected by the extreme values.

\section{Root Mean square error (RMSE):}

It is an often used measure of the difference between values predicted by a model and those actually observed from the thing being modeled. RMSE is one of the commonly used error index statisticsEq. (4).

$$
\operatorname{RMSE}=\sqrt{\frac{1}{n} \sum_{j=1}^{n}\left(x_{j}-y_{j}\right)^{2}}
$$

where, $x_{j}$ is the predicted value and $y_{j}$ is the actual value.

The RMSE is suited to iterative algorithms and is a better measure for high values. It offers a general picture of the errors involved in the prediction but is also sensitive to high values.

\section{Mean absolute error (MAE):}

The MAE is computed through a term-by-term comparison of the relative error in the prediction with respect to the actual value of the variableEq. (5).

$$
\mathrm{MAE}=\frac{1}{\mathrm{n}} \sum_{\mathrm{j}=1}^{\mathrm{n}}\left|\mathrm{x}_{\mathrm{j}}-\mathrm{y}_{\mathrm{j}}\right|
$$

where, $x_{j}$ is the predicted value and $y_{j}$ is the actual value. The performance of the ANN based models can be compared to that of Model Tree based models, on the basis of these criteria tabulated in Tables 2-3. The mean absolute error has the advantage that it does not distinguish between the over- and under-estimation and does not get too much influenced by higher values. The lower the value of MAE the better is the forecasting performance. 